\title{
Self-Powered Wireless Sensor Network for Automated Corrosion Prediction of Steel Reinforcement
}

\author{
Dan Su, ${ }^{1,2}$ Ye Xia ${ }^{1},{ }^{1}$ and Robert Yuan ${ }^{3}$ \\ ${ }^{1}$ Tongji University, Shanghai, China \\ ${ }^{2}$ Embry Riddle Aeronautical University, Daytona Beach, FL, USA \\ ${ }^{3}$ Lamar University, Beaumont, TX, USA \\ Correspondence should be addressed to Ye Xia; yxia@tongi.edu.cn
}

Received 25 July 2017; Revised 31 October 2017; Accepted 16 November 2017; Published 8 January 2018

Academic Editor: Young-Jin Cha

Copyright (c) 2018 Dan Su et al. This is an open access article distributed under the Creative Commons Attribution License, which permits unrestricted use, distribution, and reproduction in any medium, provided the original work is properly cited.

Corrosion is one of the key issues that affect the service life and hinders wide application of steel reinforcement. Moreover, corrosion is a long-term process and not visible for embedded reinforcement. Thus, this research aims at developing a self-powered smart sensor system with integrated innovative prediction module for forecasting corrosion process of embedded steel reinforcement. Vibration-based energy harvester is used to harvest energy for continuous corrosion data collection. Spatial interpolation module was developed to interpolate corrosion data at unmonitored locations. Dynamic prediction module is used to predict the long-term corrosion based on collected data. Utilizing this new sensor network, the corrosion process can be automated predicted and appropriate mitigation actions will be recommended accordingly.

\section{Introduction}

Corrosion is a deterioration process that would alternate the properties of the material because of a reaction with its environment. Similar to other natural hazards and environmental attacks, corrosion can cause dangerous and expensive damage to different objects from automobiles to pipelines, bridges, and other essential infrastructure systems. Furthermore, the aging infrastructure is one of the most serious problems faced by our society today and corrosion is one of the most severe environmental attacks that affects the service life and functionality of aging infrastructure.

The corrosion of embedded steel reinforcement is one of the principal causes of deterioration of reinforced concrete. It is presumed that when the embedded steel is protected from air by a thick cover of a low permeability concrete, the corrosion problem of steel would not arise. But in reality, this may not be entirely true since many properly built reinforced and prestressed concrete structures show premature deterioration due to steel corrosion. Rebar corrosion is one of the major forms of environmental attack to reinforced concrete, which may lead to reduction in strength, serviceability, and aesthetics of the structure, as well as affect the application of reinforcement. The corrosion of embedded steel reinforcement will greatly affect the performance, functionality, and serviceability of the structure.

The damage to concrete resulting from the corrosion of embedded steel is visible in the form of expansion, cracking, and eventual spalling of the cover $[1,2]$. Besides the loss of cover, a reinforced concrete member suffers structural damage due to loss of bond between steel and concrete and loss of rebar cross-sectional area and its functionality.

Because the corrosion occurs on the embedded reinforcement, the detection of corrosion can be extremely difficult. At early ages, coring sample was the only method to detect the corrosion. However, the coring would only indicate the corrosion condition at the coring location but would not reveal the true condition of structure as a whole. Therefore, corrosion detection technologies were developed including chain drag method (ASTM D4580-12), electrochemical half-cell potential (HCP), Tafel extrapolation technique (TP), linear polarization resistance (LPR) [3-5], macrocell 
current (MC) [6], radio-frequency identification (RFID), and sacrificial sensors (SS).

Over the past decades, number of researches have been performed to develop efficient monitoring methods and techniques. Electrochemical methods were investigated and examined at early stage of corrosion monitoring research [7-9]. Later, Baronio et al. [10] performed steel corrosion monitoring based on potential measurements. El-Mahdy et al. [11] conducted electrochemical corrosion monitoring under cyclic wet-dry conditions. Elsener [12] studied the microcell corrosion process of steel in concrete. Montemor et al. [13] presented an overview of chloride-induced corrosion process and monitoring techniques. Moreover, various techniques including galvanostatic pulse technique [14, 15], acoustic emission method [16-18], electrochemical impedance spectroscopy (EIS) $[19,20]$, and electrochemical noise analysis (ENA) method [19] were developed. Various types of sensors and reference electrodes were developed for corrosion monitoring [21-28]. Automatic system [29], remote corrosion monitoring system [30], 3-D monitoring system [31], and multielectrode system [32] were also developed recently. Performance of different corrosion monitoring techniques were reviewed, compared, and assessed [33-35]. In addition, some of the researches focused on evaluating/ modeling of chloride ingress in concrete based on laboratory and field measured data [36-39].

Initiation time of steel reinforcement corrosion is another important parameter to predict and understand corrosion mechanism of steel reinforcement. Daigle et al. [36] proposed a formula to predict the time of corrosion initiation compose parameters of concrete cover, chloride threshold, and chloride concentration. There are many factors affecting the corrosion rate including temperature, oxygen supply, relative humidity, chloride concentration, alkalinity, resistivity, galvanic interaction, and rust layer formation. There are three main approaches that developed over the years to estimate the corrosion rate [40]: (1) models based on electrochemistry, (2) models related to a diffusion-limited access of oxygen, and (3) models in the form of empirical relations.

Besides corrosion detection, corrosion prediction is also very important in mitigating corrosion damage and associated with deterioration. Over the years, several corrosion prediction methods have been developed by the researchers. Among these prediction methods, some of them focus on the prediction of corrosion rate while other methods focus on prediction of service life of reinforced concrete. While prediction of service life of reinforced concrete is important, corrosion rate or section losses of reinforcement would be a more appropriate parameter to evaluate the performance of the reinforcement in resisting corrosion. As summarized in Figure 1, there are four types of approaches for prediction of corrosion rate [40]: (1) physics-based models, (2) empirical models, (3) statistical prediction models based on various statistical techniques, and (4) heuristic data model.

For physics-based models, there are several approaches that can be used to model the reinforcement corrosion based on electrochemistry, diffusion-limited access of oxygen, and volume-discretization method. The physics-based model developed based on electrochemistry is the most

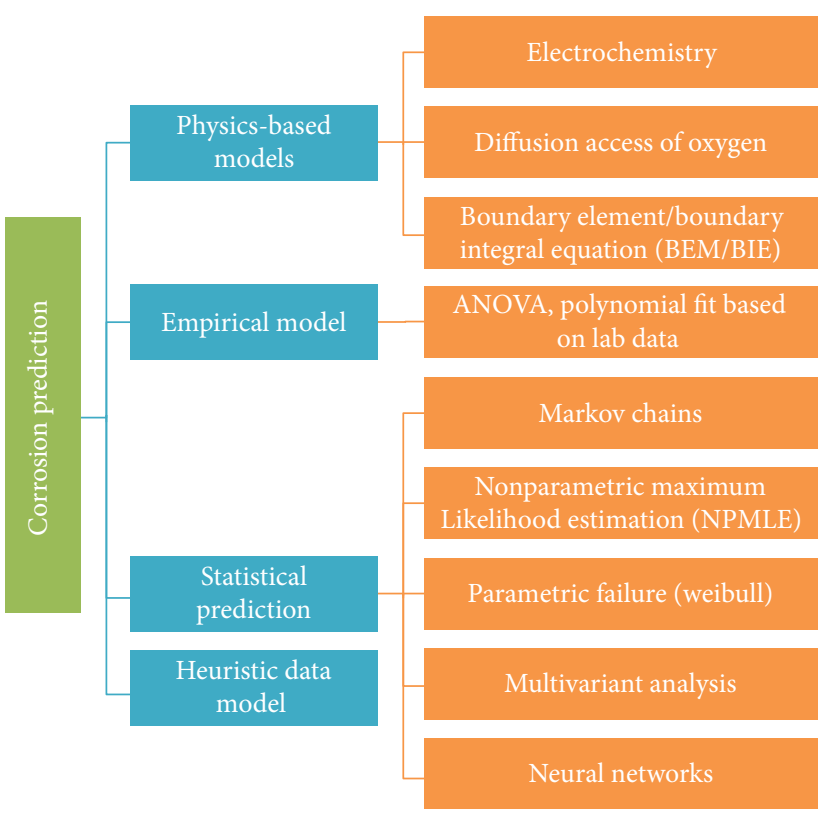

FIgURE 1: Corrosion prediction method.

common approach. Many researches have been performed to develop a complex corrosion model based on electrochemical principles and Butler-Volmer kinetics [40-43]. Advanced data filtering method and computer programs were also developed in recent years $[44,45]$. However, a great amount of details are required for the utilization of these models. Thus, it is impractical for practicing engineers to apply them for the prediction of corrosion [40]. Physicsbased models can also be developed based on diffusionlimited access of oxygen. It is known that the access of $\mathrm{O}_{2}$ at the steel surface in the cathodic zone of rebars is directly related to the corrosion reaction rate. Kobayashi and Shuttoh [46] found that the moisture content of concrete greatly affects the $\mathrm{O}_{2}$ diffusion efficient. Sudjono and Seki [47] concluded that the coefficient of $\mathrm{O}_{2}$ diffusion decreases near linearly when the water content increased from 0 to $80 \%$. Boundary element method/boundary integral equation (BEM/BIE) is another physics-based method. BEM/BIE uses Faraday's law for boundary motion to surface flux and uses polarization curves to fit boundary values into the integral equation. One advantage of BEM/BIE is it can incorporate other physical phenomena that impacts corrosion such as stress and impressed current cathodic protection into calculation. On the other hand, BEM/BIE needs detailed polarization curves which is site-specific to each specimen, electrolytic environment, stress, time, and other factors thus is not very practical to apply.

Corrosion prediction models can also be developed based on empirical relations. Siemes et al. [48] proposed a typical empirical model $V_{\text {corr }}=m_{o} / \gamma \prod F_{i}$, where $V_{\text {corr }}$ is the corrosion rate, $m_{o}$ is the factor given by the corrosion rate versus electrical resistivity, $\gamma$ is the electrical resistivity of the concrete, and $F_{i}$ is the factor influencing the local corrosion rate including chloride corrosion rate factor, galvanic effect factor, oxygen availability factor, and the oxide (rust) 
factor. There are several other empirical models that have been developed based on limited data from experimental studies $[49,50]$. However, these empirical models are developed based on limited experimental data and do not reflect the basic electrochemical reactions as well as the true nature of the corrosion process thus cannot be used for other cases without proper validation.

Since the reinforcement corrosion depends on many random variables such as temperature, ohmic resistance, chloride content, and exposure time, the corrosion can be predicted using statistical models. Various statistical techniques can be used including Weibull analysis, Monte Carlo simulation, Bayesian networks, Markov chains, and neural networks. However, the prediction needs to be validated and updated based on actual experimental data to ensure the accuracy of prediction. Heuristic data model is another analytical method for corrosion prediction. Heuristic models combine information from design rules, engineering lessons, and observations, and it provides another approach to predict the future corrosion trend of steel reinforcement. Recently, deep learning and machine learning methods also showed promising results in damage detection and prediction [51, 52].

Overall, these corrosion detection and monitoring techniques enable the engineers to detect and monitor the corrosion process of embedded steel reinforcement. However, the key issues related to long-term power supply, data transmission, and long-term reliability need to be addressed.

\section{Critical Issues Related to Corrosion Detection and Prediction}

Although there are many ways to detect corrosion and predict the corrosion rate, there are some critical issues that hinder the application of these methods in the industry level. These critical issues are as follows:

(1) Local to spatial:

all the previous researches are focused on detection of corrosion at various locations but did not provide a solution on interpolation of corrosion in a spatial scale, which is crucial when evaluating the overall global corrosion condition.

(2) Integration of detection and prediction:

the link between corrosion detection and prediction is missing. To be able to fully utilize the data collected from corrosion detection and take the mitigation action prior to severe corrosion, the corrosion detection and prediction should be integrated as one product.

(3) Data collection, transmission, and storage:

most of the corrosion detection techniques require power supply and wired connection, which greatly limited the broad application in the industrial level. With innovated wireless and energy harvesting technology, a wireless, battery-less sensor network is desired.

(4) Static versus dynamic self-updating:

the current corrosion prediction methods are static methods that did not consider the variation of environmental conditions and structural conditions over time.

(5) Manual versus automated:

due to lack of linkage between detection data and prediction, manual inputs and modeling are required for corrosion prediction and this procedure needs to be improved; therefore, automated prediction can be performed.

Besides these general critical issues, there are many other unsolved issues related to corrosion detection and prediction. Figure 2 presents the comparison of current and proposed corrosion prediction method.

\section{Proposed Wireless Sensor Network}

In order to develop a corrosion monitoring and prediction system that integrates monitoring, data processing, spatial interpolation, prediction, alert triggering, and decision making, the research framework depicted in Figure 3 is adopted. It contains various modules for different functions. Experimental and analytical studies is closely integrated to achieve automated corrosion prediction for embedded steel reinforcement.

3.1. Corrosion Monitoring and Data Collection Module. Due to the critical issues presented in previous sections, there is an urgent need to develop a reliable, durable, self-powered, and wireless sensor network for long-term corrosion monitoring. A corrosion monitoring sensors that coupled with energy harvesting modules allow long-term monitoring of steel rebar corrosion with minimum maintenance requirements. It is well documented that the power requirement of SHM systems is especially a problem for structures in remote areas. It is even more critical for corrosion monitoring since corrosion of steel reinforcement takes tens of years to develop thus normal battery power cannot last that long period of time. Therefore, a self-powered wireless corrosion sensor with energy harvesting feature has been developed in this research.

The main energy harvesting sources in structures are solar, thermal gradient, wind and aeroelastic vibration, and ambient mechanical vibration. There are several emerging concepts in harvesting energy from concrete structures. $\mathrm{Yu}$ et al. [53] used the corrosion energy to produce electrical energy for wireless sensors. Ye and Soga [54] developed a methodology that converts water distribution system movement to electrical energy. García and Partl [55] proposed a method to harvest energy using parallel air conduits placed inside the asphalt that generates airflow to trigger wind turbines. In general, the selection of proper energy sources depends on the power requirement, the 
Current corrosion

detection methods
Current corrosion

prediction methods

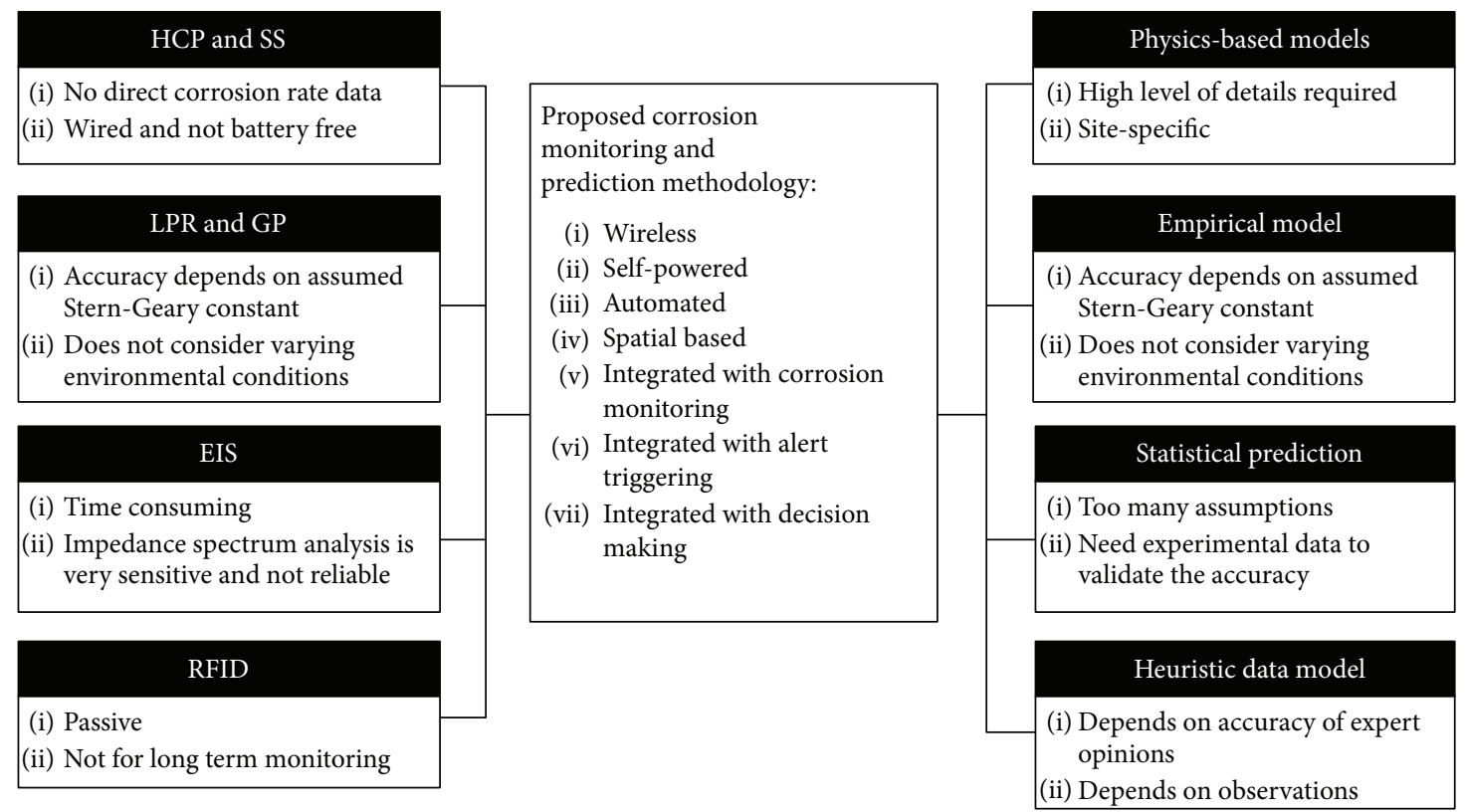

Figure 2: Comparison of current and proposed corrosion prediction methods.

installation location, and available ambient energy. As shown in Table 1, the power density that generates from different sources varies.

Currently, most of energy-harvesting devices (with the exception of solar panels) are in prototype phase and only have been tested under controlled laboratory conditions. Thus, in this research, a self-powered wireless sensor network with energy harvesting capability that can be used in harsh field conditions is developed.

Although there are many sources that can be used to harvest energy, considering the limited availability and lack of consistency for solar radiation and thermal gradient, ambient vibration is a good source of ambient energy that can be used to convert to usable electrical energy due to the fact that the majority of steel reinforced concrete structure subjected to dynamic loading including wind, seismic, machinery, and vehicular load. There are several types of vibration-based energy harvesters: piezoelectric vibration energy harvesters (PE-VEH), electrostatic vibration energy harvester (ES-VEH), and electromagnetic vibration energy harvester (EM-VEH) [57]. Due to usage of initial charging source and requirement of the electronic switch circuit during the operation, ES-VEH is not a good option in comparison with PE-VEH and EM-VEH. Comparing PE-VEH and EM-VEH, PE-VEH is used in this research due to its relatively better power density/acceleration performance.

As shown in Figure 4, for piezoelectric vibration energy harvester, a piezoelectric material is deposited on the surface of the steel reinforcement. When the reinforcement vibrates or deforms, the piezoelectric material is subjected to deformation as well. Due to the nature of piezoelectric material, the deformation will induce voltage. Figure 4(b) shows a prototype self-powered wireless corrosion sensor that has been installed in reinforced concrete deck for long-term monitoring. The total potential energy can be estimated using (1) developed by Rhimi and Lajnef [58]

$$
\begin{aligned}
U= & \frac{1}{2} \int_{V_{s}} S^{T} T d V_{s}+\frac{1}{2} \int_{V_{p}} S^{T} T d V_{p}+\frac{1}{2} \int_{V_{p}} E^{T} D d V_{p} \\
& +\frac{1}{2} \int_{L} P\left(\frac{\partial u}{\partial x}\right)^{2} d x
\end{aligned}
$$

where $S$ is strain, $T$ is stress, $E$ is electric field, $D$ is electric displacement, and $V$ is the volume of piezoelectric material.

The battery-free corrosion sensors coupled with wireless modules including gateway and base station enables continuous real-time data collection. Since communication of data consumes significant amount of energy. Thus, data transmission and routing are carefully designed to minimize the consumption of power. Data compression method is applied to reduce the data size. There are two compression algorithms: lossless and lossy compression. Because the lossless compression guarantees the integrity of data without distortion, lossless compression algorithm is used in this study. Comparing to the existing corrosion detection/monitoring system, the key features of this approach are (1) the use of energy harvesting instead of battery powered. Battery-powered sensors impose great limitation on the length of possible service life of the sensor since the sensor will be embedded with the steel reinforcement. Especially for the monitoring of a process as corrosion that takes long time to develop, the continuous power supply over tens of years is essential; another key feature is (2) the application of wireless technology. Taking advantage of state-of-the-art wireless technology to establish 


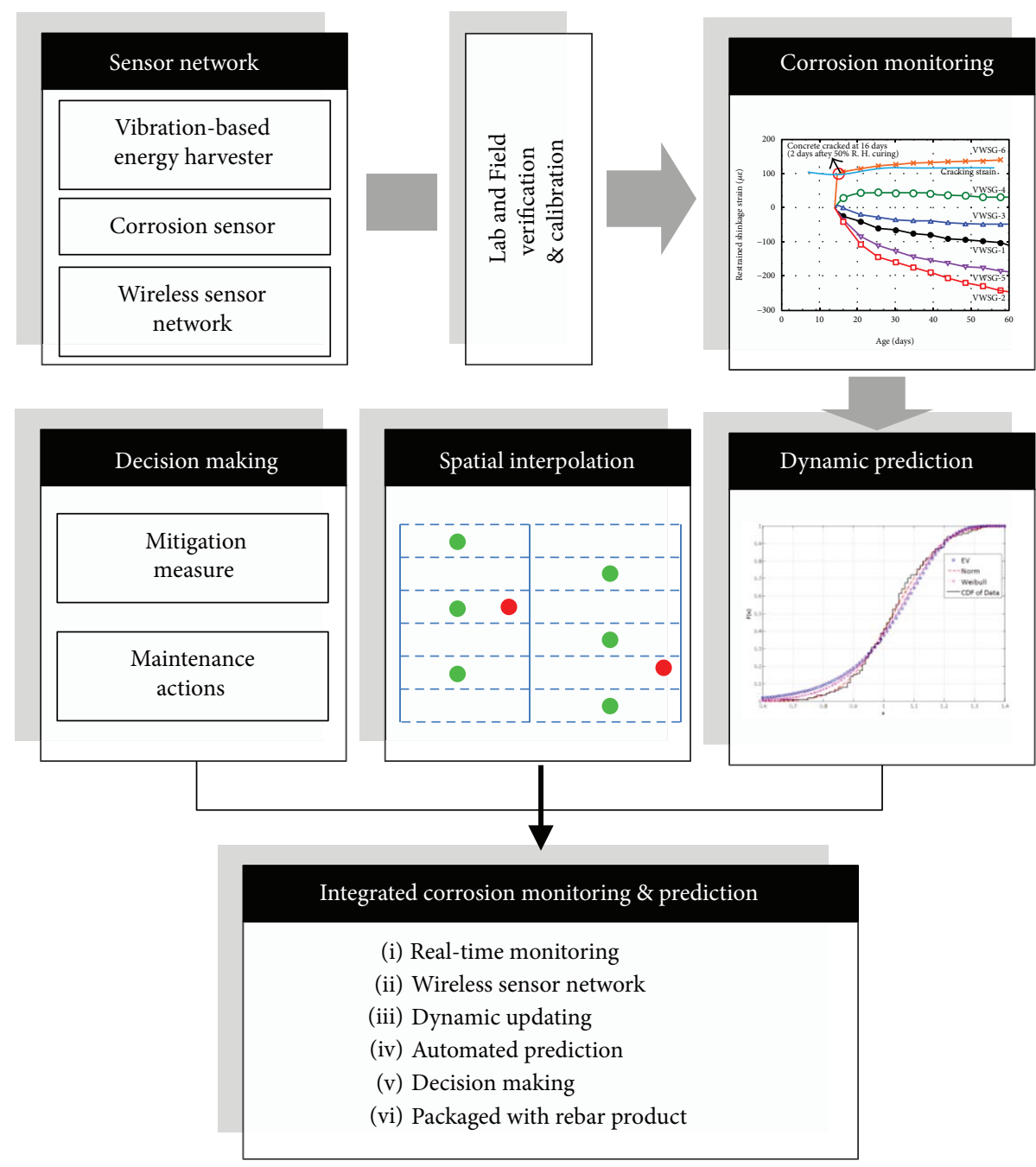

FIgURE 3: Research framework.

TABLE 1: Characteristics of various energy-harvesting techniques [56].

\begin{tabular}{lcccc}
\hline & Conditions & Power density & Area or volume & Energy/day \\
\hline Vibration & $1 \mathrm{~m} / \mathrm{s}^{2}$ & $100 \mu \mathrm{W} / \mathrm{cm}^{3}$ & $1 \mathrm{~cm}^{3}$ & $8.64 \mathrm{~J}$ \\
Solar & Outdoors & $7500 \mu \mathrm{W} / \mathrm{cm}^{2}$ & $1 \mathrm{~cm}^{2}$ & 324 J (assuming light is available for $50 \%$ of the time) \\
Solar & Indoors & $100 \mu \mathrm{W} / \mathrm{cm}^{2}$ & $1 \mathrm{~cm}^{2}$ & $4.32 \mathrm{~J}$ (assuming light is available for $50 \%$ of the time) \\
Thermal & $\Delta T=5^{\circ} \mathrm{C}$ & $60 \mu \mathrm{W} / \mathrm{cm}^{2}$ & $1 \mathrm{~cm}^{2}$ & $2.59 \mathrm{~J}$ (assuming light is available for $50 \%$ of the time) \\
\hline
\end{tabular}

a wireless sensor network to replace the traditional wired sensor network is a significant advancing.

3.2. Spatial Interpolation Module. Because only limited number of sensors can be instrumented in the field, in order to obtain the corrosion condition from the structure level, a spatial interpolation algorithm is needed. As illustrated in Figure 5, a series of sensors will be installed at selected locations (green and purple dots). Data from some of the sensors (green dots) will be used as input for spatial interpolation model while data from other sensors (purple dots) will be used to validate the model. Various input/validation sensor combinations will be examined to identify the most accurate interpolation model to predict the corrosion at unknown locations (red dots).

The spatial correlation of different locations will be examined by spatial statistical simulation with semivariogram. Semivariogram is a statistical tool that measures regionalized spatial variable $x\left(\mathbf{u}_{\alpha}\right)$, where $\mathbf{u}_{\alpha}$ is the coordinate vector at each of the observation points in a two or three dimensional space [59]. The empirical semivariogram $\gamma(\mathbf{h})$ can be calculated using

$$
\gamma(\mathbf{h})=\frac{1}{2 N(\mathbf{h})} \sum_{\alpha=1}^{N(\mathbf{h})}\left[x\left(\mathbf{u}_{\alpha}\right)-x\left(\mathbf{u}_{\alpha}+h\right)\right]^{2},
$$




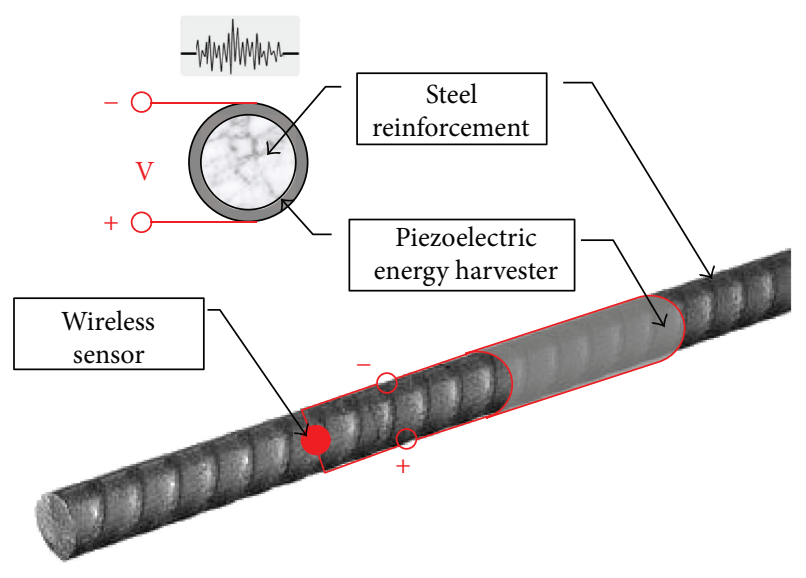

(a)

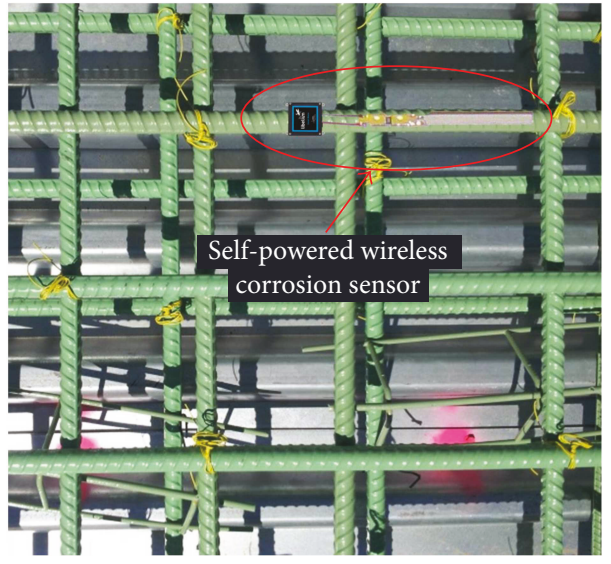

(b)

FIgURE 4: (a) Scheme for wireless corrosion sensor and (b) prototype.

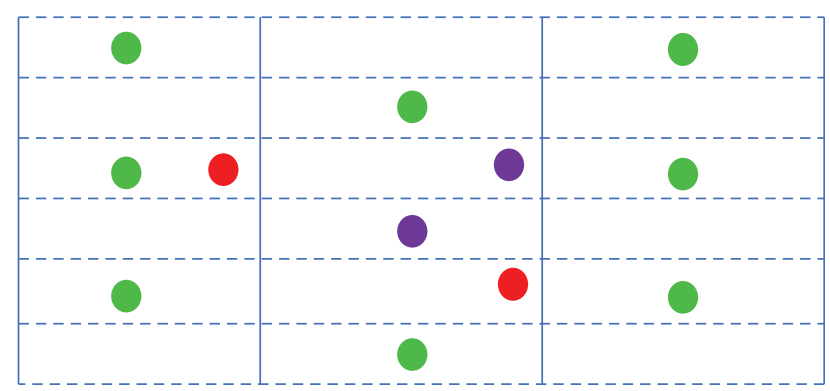

Sensor location (input)

Sensor location (validation)

Unknown location

Figure 5: Illustration of spatial interpolation.

where $\gamma(\mathbf{h})$ is the estimated value of the semivariance for vector $\mathbf{h} ; N(\mathbf{h})$ is the number of experimental pairs separated by vector $\mathbf{h}$; and $x\left(\mathbf{u}_{\alpha}\right)$ is a spatial variable.

Various statistical models including spherical, exponential, Gaussian, linear, and power models will be used to fit the experimental semivariograms. The model that produces the least error will be used for further analysis.

There are several spatial interpolation methods available including arithmetic mean method, the nearest neighbor method, distance weighted method, and polynomial interpolation method. Because kriging method considers the spatial structure properties and spatial correlations, kriging will be used for spatial interpolation modeling. Using the structural properties of semivariogram and the initial set of experimental data values, kriging is capable of making optimal, accurate estimates of regionalized variable at unknown locations. Spatial interpolated prediction $\underset{\mathrm{ok}}{Z}\left(x_{0}\right)$ from ordinary kriging $(\mathrm{OK})$ is defined as follows:

$$
\underset{\mathrm{ok}}{Z}\left(x_{0}\right)=\sum_{\alpha=1}^{n} \lambda_{\alpha}^{\mathrm{ok}} Z\left(x_{\alpha}\right)
$$

where $\lambda_{\alpha}^{\mathrm{ok}}$ is the OK weights and the summation should be equal to 1 . Thus, the key to an appropriate prediction is selecting appropriate weights for respective available observations. The criteria of selection are to minimize the kriging variance $\sigma_{\mathrm{ok}}^{2}\left(x_{0}\right)=-\gamma(0)-\sum_{\alpha=1}^{n} \sum_{\beta=1}^{n} \lambda_{\alpha}^{\mathrm{ok}} \lambda_{\beta}^{\mathrm{ok}} \gamma$ $\left(x_{\alpha}-x_{\beta}\right)+2 \sum_{\alpha=1}^{n} \lambda_{\alpha}^{\mathrm{ok}} \gamma\left(x_{\alpha}-x_{0}\right)$, where $\gamma$ is the estimated value of the semivariance. This minimization process can be done using Lagrange multipliers.

3.3. Corrosion Prediction Module. Corrosion prediction can be mystical since the corrosion of steel reinforcement is a long process and it is invisible and even is not noticeable unless the concrete cover got peeled off. However, on the other hand, accurate prediction of corrosion is very important and extremely helpful for the owner to develop a more efficient maintenance plan and take mitigation measures in advance. As presented in previous sections, there are several corrosion prediction methods that have been developed. However, there are some critical issues that limited the further and wide application of these prediction methods. Furthermore, since there is no direct linkage between data collection and prediction, tremendous effects are needed to perform the corrosion prediction and there is no practical way to validate the accuracy of the prediction. Therefore, the authors developed a corrosion prediction algorithm that is automated, self-updating, and incorporated with corrosion monitoring and data collection.

For time-related variation or development, there are two quantitative forecasting methods that can be used: (1) causal models and (2) time series models. Comparing to causal models, time series models take trend, cyclical, seasonal, and irregular events into consideration and its progressive feature provides a unique updating algorithm which greatly improves the accuracy of prediction. Thus, automatic time series forecasting is used for corrosion prediction in this study. Many predictive models have been investigated including linear, quadratic, exponential, autoregressive, and state-space models. For automatic time series forecasting algorithm, if the observed corrosion rate is denoted by $y_{1}$, 


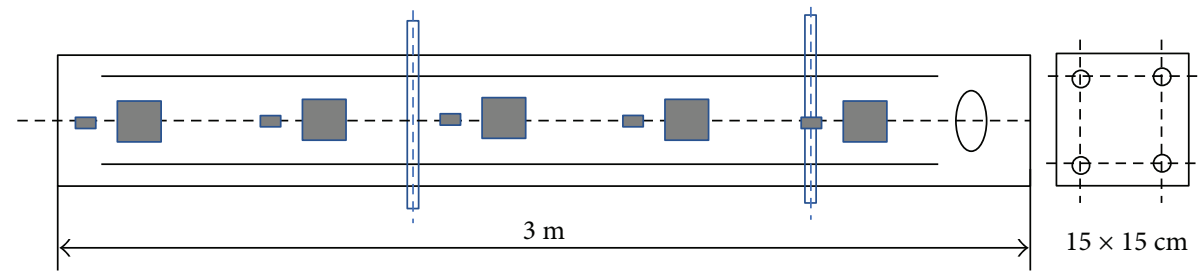

FIGURE 6: Specimens prepared for field exposure [62].

$y_{2}, \ldots, y_{n}$. A forecast denoted as $\widehat{y}_{t+h \mid t}$ at $h$ periods ahead can be estimated using $\hat{y}_{t+h \mid t}=l_{t}+b_{t} h+s_{t-m}+h_{m}^{+}$, where $m$ is the length of seasonality, $l_{t}$ represents the level of the series, $b_{t}$ represents the growth, $s_{t}$ is the seasonal component, and $h_{m}^{+}=[(h-1) \bmod m]+1 . l_{t}, b_{t}$, and $s_{t}$ can be calculated using [60]

$$
\begin{aligned}
& l_{t}=\alpha\left(y_{t}-s_{t-m}\right)+(1-\alpha)\left(l_{t-1}+b_{t-1}\right), \\
& b_{t}=\beta^{*}\left(l_{t}-l_{t-1}\right)+\left(1-\beta^{*}\right) b_{t-1}, \\
& s_{t}=\gamma\left(y_{t}-l_{t-1}-b_{t-1}\right)+(1-\gamma) s_{t-m},
\end{aligned}
$$

where the initial state of each parameter $l_{0}, b_{0}$, and $s_{1-m}, \ldots, s_{0}$ and the smoothing parameters $\alpha, \beta^{*}$, and $\gamma$ can be estimated from experimental data.

To evaluate the accuracy of the predictive models, measures such as mean squared error (MSE) can be applied. However, it might difficult to draw reliable conclusions because of too few out-of-sample errors. Thus, a penalized likelihood method such as Akaike's information criterion (AIC) that based on in-sample fit has been proven to be a better approach and is used in this study to evaluate the accuracy of the predictive models. The formulas for AIC method are presented in the following equations:

$$
\begin{aligned}
\mathrm{AIC} & =L^{*}\left(\widehat{\theta}, \widehat{x}_{0}\right)+2 q, \\
L^{*}\left(\theta, x_{0}\right) & =n \log \left(\sum_{t=1}^{n} \varepsilon_{t}^{2}\right)+2 \sum_{t=1}^{n} \log \left|r\left(x_{t-1}\right)\right|,
\end{aligned}
$$

where $L^{*}\left(\widehat{\theta}, \widehat{x}_{0}\right)$ is the maximum likelihood function, $\theta=$ $(\alpha, \beta, \gamma, \phi)^{\prime}, x_{0}=\left(l_{0}, b_{0}, s_{0}, s_{-1}, \ldots, s_{-m+1}\right)^{\prime}, n$ is the number of observations, $\varepsilon_{t}=y_{t}-\mu_{t}$ is the one-step forecast error at time t. $q$ is the number of parameters in $\theta$ plus the number of free states in $x_{0}$. The model that produce the least AIC will be selected for corrosion prediction.

The framework for automatic prediction algorithm can be summarized as (1) for each set of experimental data, apply all models and optimize the smoothing parameters and initial state variables for each model; (2) calculate AIC and select the best model based on AIC; (3) produce prediction at various time points using the best model with optimized parameters; (4) and continuously update the prediction based on newly collected experimental data.

\section{Proof of Concept}

Due to the lack of reliable sensors that can be used for longterm corrosion monitoring, very limited experimental study has been performed on long-term corrosion performance of embedded reinforcement especially under field conditions. Flint and Cox [61] investigated the resistance of stainless steel partly embedded in concrete to corrosion by seawater under lab conditions. However, no continuous data was collected on corrosion of steel. Gartner et al. [62] evaluated the longterm corrosion performance of embedded reinforcement based on monitoring data for more than five years under various conditions. Multielectrodes coupled with stainless or carbon steel electrical resistance (ER) probes were embedded in reinforced concrete columns which placed vertically in sea water under a bridge. As shown in Figure 6, corrosion was monitored at five different exposure zones: the in-water zone, the zone below the surface, the tidal zone, the splash zone, and the dry zone. The monitoring lasted for five years with measurements being taken several times a year. In order to validate the prediction algorithm that developed in this study, the long-term corrosion monitoring data collected by Gartner et al. [62] was used.

Figures 7 and 8 present the comparison between experimental data collected by Gartner et al. [62] and predicted values using the algorithm presented in this research for tidal zone and in-water zone, respectively. As shown in the comparison, using the prediction algorithm presented in this research, the prediction accurately represented the trends of corrosion at different locations for a period of 5 years. The prediction captured seasonal variation and the trends of peak values. Abnormal drop was observed in measured current at tidal zone around 1100 days (Figure 7). Since the overall trend is upward, it is suspected the drop is because of improper measurement or reading. Furthermore, due to the self-updating nature of prediction algorithm, the prediction will become even more accurate when more data is available.

\section{Conclusions}

Although the corrosion of embedded steel reinforcement is one of the major attacks that affects the serviceability and service life of concrete infrastructures, there is no existing technology that could provide reliable long-term monitoring data due to the limitation on battery life and data communication, let alone future predication. In this paper, an automated corrosion prediction framework was developed for embedded steel reinforcement. With a self-powered wireless sensor network incorporated with spatial interpolation module and corrosion prediction module, the long-term corrosion of embedded reinforcement can be monitored and predicted efficiently and accurately. Prototype sensors were developed and installed in a reinforced concrete bridge deck. 


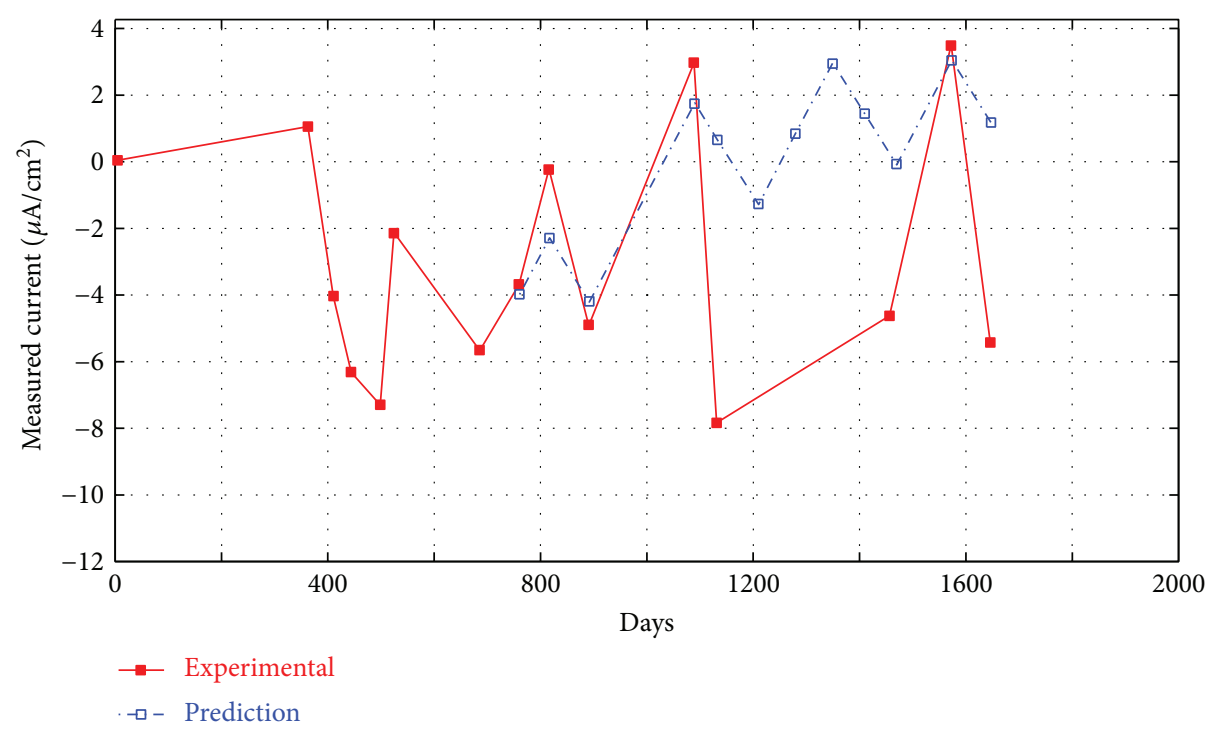

FigURE 7: Comparison between experimental data and prediction (tidal zone).

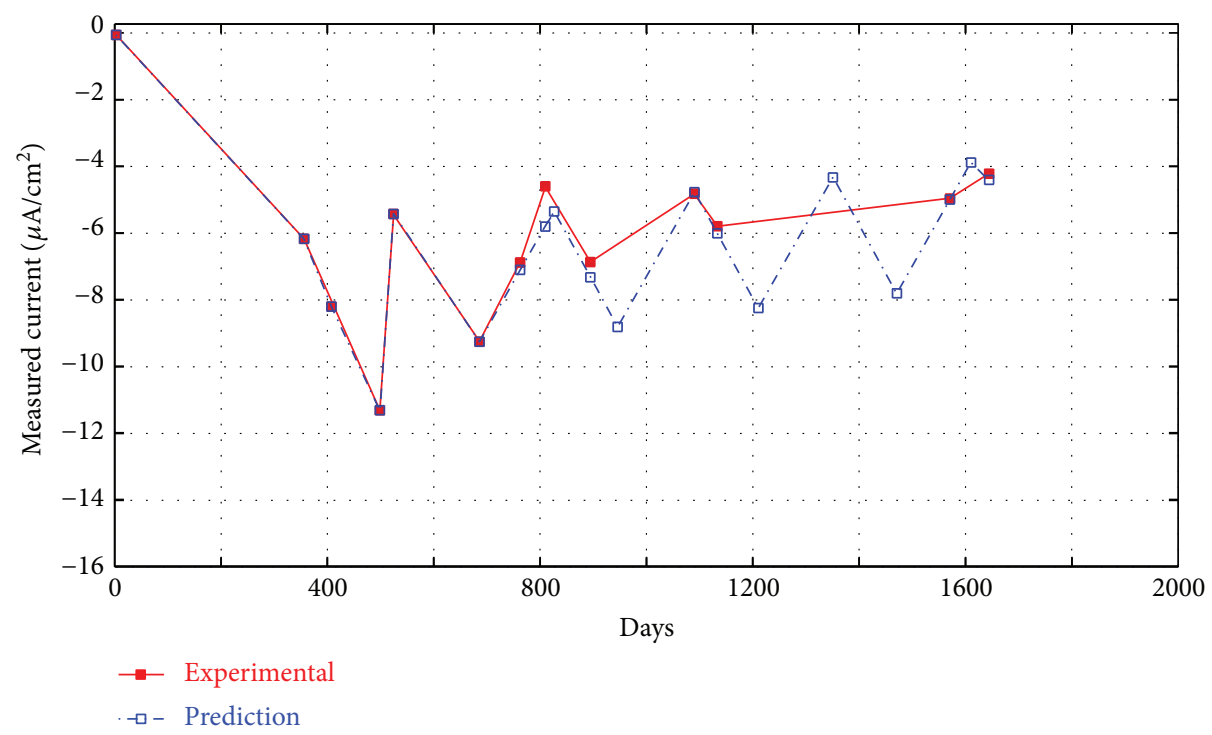

Figure 8: Comparison between experimental data and prediction (in-water zone).

In addition, the prediction algorithm was compared and examined using five years of monitoring data and the prediction accurately represented the trends of corrosion at different locations.

\section{Conflicts of Interest}

The authors declare that they have no conflicts of interest.

\section{Acknowledgments}

The authors would like to thank Dr. Bhaskar Yalamanchili and Gerdau Ameristeel for their valuable inputs to the research presented herein. The support for the corresponding author by National Natural Science Foundation of China (Grant No. 51508405), Ministry of Transport of the People's
Republic of China (Grant No. 2015318J38230), Science and Technology Commission of Shanghai Municipality (Grant Nos. 17DZ1204301 and 17DZ1204103), and the Fundamental Research Funds for the Central Universities is greatly acknowledged.

\section{References}

[1] P. D. Cady, "Chapter 19-corrosion of reinforcing steel," in Significance of Tests and Properties of Concrete and ConcreteMaking Materials, pp. 275-275-25, ASTM International, West Conshohocken, PA, USA, 1978.

[2] Y. Xia, H. Nassif, and D. Su, "Early-age cracking in high performance concrete decks of a curved steel girder bridge," Journal of Aerospace Engineering, vol. 30, no. 2, article B4016003, 2017. 
[3] S. Ahmad, "Reinforcement corrosion in concrete structures, its monitoring and service life prediction-a review," Cement and Concrete Composites, vol. 25, no. 4-5, pp. 459-471, 2003.

[4] N. S. Berke, V. Chaker, and D. Whiting, Corrosion Rates in Steel in Concrete, ASTM, West Conshohocken, PA, USA, 1990.

[5] H. Böhni, Ed., Corrosion in Reinforced Concrete Structures, Elsevier, 2005.

[6] M. Raupach, "Chloride-induced macrocell corrosion of steel in concrete-theoretical background and practical consequences," Construction and Building Materials, vol. 10, no. 5, pp. 329-338, 1996.

[7] M. Pourbaix, "Applications of electrochemistry in corrosion science and in practice," Corrosion Science, vol. 14, no. 1, pp. 25-82, 1974.

[8] P. R. Vassie and M. McKenzie, "Electrode potentials for on-site monitoring of atmospheric corrosion of steel," Corrosion Science, vol. 25, no. 1, pp. 1-13, 1985.

[9] G. K. Glass, C. L. Page, N. R. Short, and S. W. Yu, "An investigation of galvanostatic transient methods used to monitor the corrosion rate of steel in concrete," Corrosion Science, vol. 35, no. 5-8, pp. 1585-1592, 1993.

[10] G. Baronio, M. Berra, L. Bertolini, and T. Pastore, "Steel corrosion monitoring in normal and total-lightweight concretes exposed to chloride and sulphate solutions part I: potential measurements," Cement and Concrete Research, vol. 26, no. 5, pp. 683-689, 1996.

[11] G. A. El-Mahdy, A. Nishikata, and T. Tsuru, "Electrochemical corrosion monitoring of galvanized steel under cyclic wetdry conditions," Corrosion Science, vol. 42, no. 1, pp. 183194, 2000

[12] B. Elsener, "Macrocell corrosion of steel in concrete - implications for corrosion monitoring," Cement and Concrete Composites, vol. 24, no. 1, pp. 65-72, 2002.

[13] M. F. Montemor, A. M. P. Simões, and M. G. S. Ferreira, "Chloride-induced corrosion on reinforcing steel: from the fundamentals to the monitoring techniques," Cement and Concrete Composites, vol. 25, no. 4-5, pp. 491-502, 2003.

[14] S. Sathiyanarayanan, P. Natarajan, K. Saravanan, S. Srinivasan, and G. Venkatachari, "Corrosion monitoring of steel in concrete by galvanostatic pulse technique," Cement and Concrete Composites, vol. 28, no. 7, pp. 630-637, 2006.

[15] H. W. Song and V. Saraswathy, "Corrosion monitoring of reinforced concrete structures-a," International Journal of Electrochemical Science, vol. 2, pp. 1-28, 2007.

[16] M. Fregonese, H. Idrissi, H. Mazille, L. Renaud, and Y. Cetre, "Initiation and propagation steps in pitting corrosion of austenitic stainless steels: monitoring by acoustic emission," Corrosion Science, vol. 43, no. 4, pp. 627-641, 2001.

[17] M. S. Weng, S. E. Dunn, W. H. Hartt, and R. P. Brown, "Application of acoustic emission to detection of reinforcing steel corrosion in concrete," Corrosion, vol. 38, no. 1, pp. 914, 1982.

[18] P. Ziehl and M. ElBatanouny, "Acoustic emission monitoring for corrosion damage detection and classification," Corrosion of Steel in Concrete Structures, pp. 193-209, 2016.

[19] G. Qiao and J. Ou, "Corrosion monitoring of reinforcing steel in cement mortar by EIS and ENA," Electrochimica Acta, vol. 52, no. 28, pp. 8008-8019, 2007.

[20] A. Nishikata, Q. Zhu, and E. Tada, "Long-term monitoring of atmospheric corrosion at weathering steel bridges by an electrochemical impedance method," Corrosion Science, vol. 87, pp. 80-88, 2014.

[21] Y. Chen, F. Tang, Y. Tang, M. J. O’Keefe, and G. Chen, "Mechanism and sensitivity of $\mathrm{Fe}-\mathrm{C}$ coated long period fiber grating sensors for steel corrosion monitoring of RC structures," Corrosion Science, vol. 127, pp. 70-81, 2017.

[22] S.-G. Dong, C.-J. Lin, R.-G. Hu, L.-Q. Li, and R.-G. Du, "Effective monitoring of corrosion in reinforcing steel in concrete constructions by a multifunctional sensor," Electrochimica Acta, vol. 56, no. 4, pp. 1881-1888, 2011.

[23] G. S. Duffó and S. B. Farina, "Development of an embeddable sensor to monitor the corrosion process of new and existing reinforced concrete structures," Construction and Building Materials, vol. 23, no. 8, pp. 2746-2751, 2009.

[24] A. Legat, "Monitoring of steel corrosion in concrete by electrode arrays and electrical resistance probes," Electrochimica Acta, vol. 52, no. 27, pp. 7590-7598, 2007.

[25] S. Y. Li, Y.-G. Kim, S. Jung, H.-S. Song, and S.-M. Lee, "Application of steel thin film electrical resistance sensor for in situ corrosion monitoring," Sensors and Actuators B: Chemical, vol. 120, no. 2, pp. 368-377, 2007.

[26] V. Maruthapandian, V. Saraswathy, and S. Muralidharan, "Development of solid state embeddable reference electrode for corrosion monitoring of steel in reinforced concrete structures," Cement and Concrete Composites, vol. 74, pp. 100108, 2016.

[27] S. Muralidharan, V. Saraswathy, L. J. Berchmans, K. Thangavel, and K. Y. Ann, "Nickel ferrite $\left(\mathrm{NiFe}_{2} \mathrm{O}_{4}\right)$ : a possible candidate material as reference electrode for corrosion monitoring of steel in concrete environments," Sensors and Actuators B: Chemical, vol. 145, no. 1, pp. 225-231, 2010.

[28] T. Parthiban, R. Ravi, and G. T. Parthiban, "Potential monitoring system for corrosion of steel in concrete," Advances in Engineering Software, vol. 37, no. 6, pp. 375-381, 2006.

[29] A. Poursaee, "Automatic system for monitoring corrosion of steel in concrete," Advances in Engineering Software, vol. 40, no. 11, pp. 1179-1182, 2009.

[30] G. Qiao, G. Sun, Y. Hong, Y. Qiu, and J. Ou, "Remote corrosion monitoring of the RC structures using the electrochemical wireless energy-harvesting sensors and networks," NDT and E International, vol. 44, no. 7, pp. 583-588, 2011.

[31] P.-A. Itty, M. Serdar, C. Meral et al., "In situ 3D monitoring of corrosion on carbon steel and ferritic stainless steel embedded in cement paste," Corrosion Science, vol. 83, pp. 409-418, 2014.

[32] A. Brenna, L. Lazzari, and M. Ormellese, "Monitoring chloride-induced corrosion of carbon steel tendons in concrete using a multi-electrode system," Construction and Building Materials, vol. 96, pp. 434-441, 2015.

[33] A. Česen, T. Kosec, and A. Legat, "Characterization of steel corrosion in mortar by various electrochemical and physical techniques," Corrosion Science, vol. 75, pp. 47-57, 2013.

[34] I. Martínez and C. Andrade, "Examples of reinforcement corrosion monitoring by embedded sensors in concrete structures," Cement and Concrete Composites, vol. 31, no. 8, pp. 545-554, 2009.

[35] S. P. Karthick, S. Muralidharan, V. Saraswathy, and K. Thangavel, "Long-term relative performance of embedded sensor and surface mounted electrode for corrosion monitoring of steel in concrete structures," Sensors and Actuators B: Chemical, vol. 192, pp. 303-309, 2014. 
[36] L. Daigle, Z. Lounis, and D. Cusson, "Numerical prediction of early-age cracking and corrosion in high performance concrete bridges - case study," in TAC Annual Conference 2004 - Transportation Innovation-Accelerating the Pace, pp. 1-20, Quebec City, QC, Canada, 2004.

[37] P. Goltermann, "Chloride ingress in concrete structures: extrapolation of observations," ACI Materials Journal, vol. 100, no. 2, pp. 114-119, 2003.

[38] Z. Lounis, "Probabilistic modeling of chloride contamination and corrosion of concrete bridge structures," in Fourth International Symposium on Uncertainty Modeling and Analysis, 2003. ISUMA 2003, pp. 447-451, College Park, MD, USA, September 2003, IEEE.

[39] J. Paulsson-Tralla and J. Silfwerbrand, "Estimation of chloride ingress in uncracked and cracked concrete using measured surface concentrations," ACI Materials Journal, vol. 99, no. 1, pp. 27-36, 2002.

[40] T. Maruya, K. Hsu, H. Takeda, and S. Tangtermsirikul, "Numerical modeling of steel corrosion in concrete structures due to chloride ion, oxygen and water movement," Journal of Advanced Concrete Technology, vol. 1, no. 2, pp. 147160, 2003.

[41] S. C. Kranc and A. A. Sagüés, "Calculation of extended counter electrode polarization effects on the electrochemical impedance response of steel in concrete," in Electrochemical Impedance: Analysis and Interpretation, pp. 365-365-19, ASTM International, West Conshohocken, PA, USA, 1993.

[42] S. C. Kranc and A. A. Sagüés, "Detailed modeling of corrosion macrocells on steel reinforcing in concrete," Corrosion Science, vol. 43, no. 7, pp. 1355-1372, 2001.

[43] A. Sagüés, S. C. Kranc, and B. G. Washington, "Computer modeling of corrosion and corrosion protection of steel in concrete," Concrete 2000-Economic and Durable Construction through Excellence, p. 1275, 1993.

[44] Y. L. Ding, H. W. Zhao, and A. Q. Li, "Temperature effects on strain influence lines and dynamic load factors in a steel-truss arch railway bridge using adaptive FIR filtering," Journal of Performance of Constructed Facilities, vol. 31, no. 4, article 04017024, 2017.

[45] B. Wei, G. L. Dai, Y. Wen, and Y. Xia, "Seismic performance of isolation system of rolling friction with springs," Journal of Central South University, vol. 21, no. 4, pp. 1518-1525, 2014.

[46] K. Kobayashi and K. Shuttoh, "Oxygen diffusivity of various cementitious materials," Cement and Concrete Research, vol. 21, no. 2-3, pp. 273-284, 1991.

[47] A. S. Sudjono and H. Seki, "Experimental and analytical studies on oxygen transport in various cementitious materials," Special Publication, vol. 192, pp. 721-738, 2000.

[48] A. J. M. Siemes, C. Gehlen, A. Lindvall, A. Arteaga, and H. M. Ludwig, Statistical Quantification of the Variables in the Limit State Functions, Brite-Euram, Brussels, Belgium, 1999, Summary.

[49] T. Liu and R. W. Weyers, "Modeling the dynamic corrosion process in chloride contaminated concrete structures," Cement and Concrete Research, vol. 28, no. 3, pp. 365-379, 1998.

[50] K. A. T. Vu and M. G. Stewart, "Structural reliability of concrete bridges including improved chloride-induced corrosion models," Structural Safety, vol. 22, no. 4, pp. 313-333, 2000.

[51] Y. J. Cha, W. Choi, and O. Büyüköztürk, "Deep learning-based crack damage detection using convolutional neural networks,"
Computer-Aided Civil and Infrastructure Engineering, vol. 32, no. 5, pp. 361-378, 2017.

[52] Y. J. Cha, K. You, and W. Choi, "Vision-based detection of loosened bolts using the Hough transform and support vector machines," Automation in Construction, vol. 71, pp. 181188, 2016.

[53] Y. Yu, G. Qiao, and J. Ou, "Self-powered wireless corrosion monitoring sensors and networks," IEEE Sensors Journal, vol. 10, no. 12, pp. 1901-1902, 2010.

[54] G. Ye and K. Soga, "Energy harvesting from water distribution systems," Journal of Energy Engineering, vol. 138, no. 1, pp. 7-17, 2011.

[55] A. García and M. N. Partl, "How to transform an asphalt concrete pavement into a solar turbine," Applied Energy, vol. 119, pp. 431-437, 2014.

[56] S. J. Roundy, Energy Scavenging for Wireless Sensor Nodes with a Focus on Vibration to Electricity Conversion [Ph.D. thesis], University of California, Berkeley, Berkeley, CA, USA, 2003.

[57] F. U. Khan and I. Ahmad, "Review of energy harvesters utilizing bridge vibrations," Shock and Vibration, vol. 2016, Article ID 1340402, 21 pages, 2016.

[58] M. Rhimi and N. Lajnef, "Tunable energy harvesting from ambient vibrations in civil structures," Journal of Energy Engineering, vol. 138, no. 4, pp. 185-193, 2012.

[59] V. Kumar and Remadevi, "Kriging of groundwater levels - a case study," Journal of Spatial Hydrology, vol. 6, no. 1, 2006.

[60] R. J. Hyndman and Y. Khandakar, "Automatic time series forecasting: the forecast package for R," Journal of Statistical Software, vol. 27, no. 3, 2008.

[61] G. N. Flint and R. N. Cox, "The resistance of stainless steel partly embedded in concrete to corrosion by seawater," Magazine of Concrete Research, vol. 40, no. 142, pp. 13-27, 1988.

[62] N. Gartner, T. Kosec, and A. Legat, "Monitoring of the longterm performance of stainless steel reinforcement in saline environments," BHM Berg- und Hüttenmännische Monatshefte, vol. 161, no. 1, pp. 44-49, 2016. 


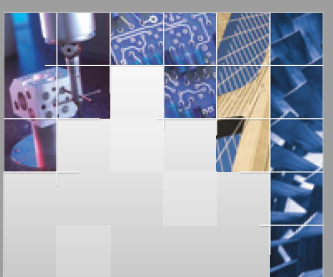

\section{Enfincering}
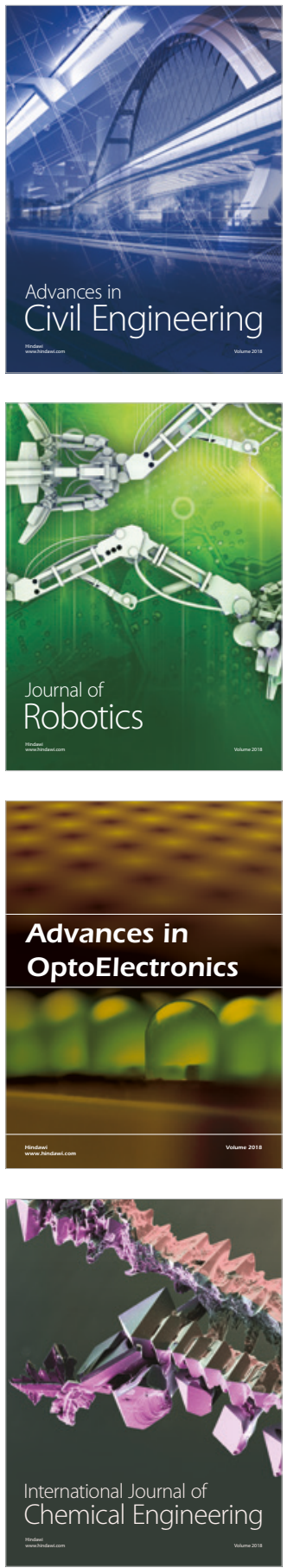

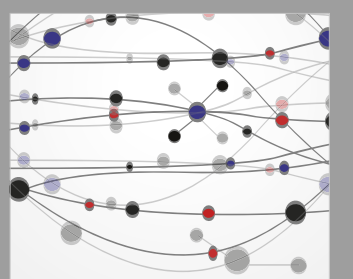

\section{Rotating \\ Machinery}

The Scientific World Journal

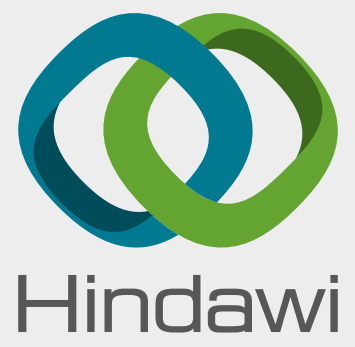

Submit your manuscripts at

www.hindawi.com
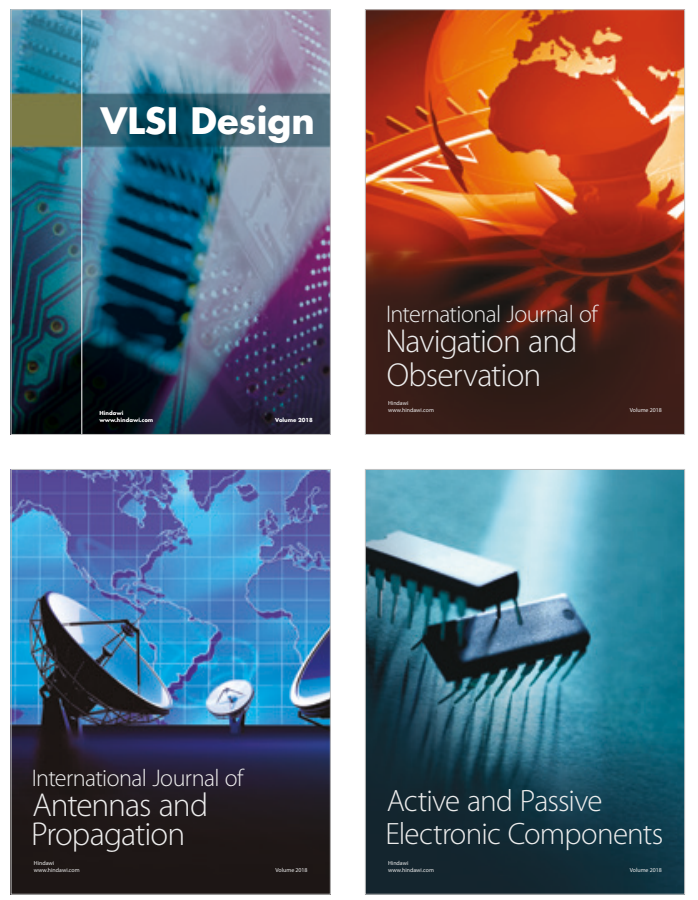
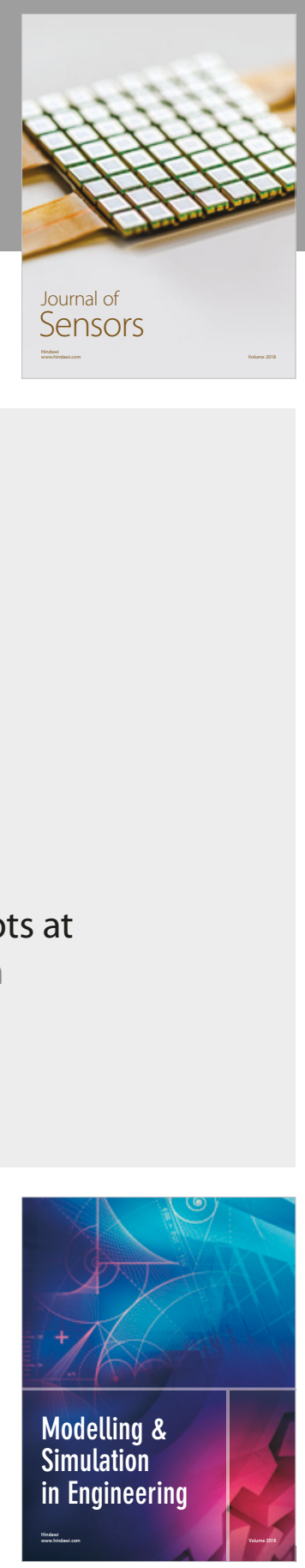

\section{Advances \\ Multimedia}
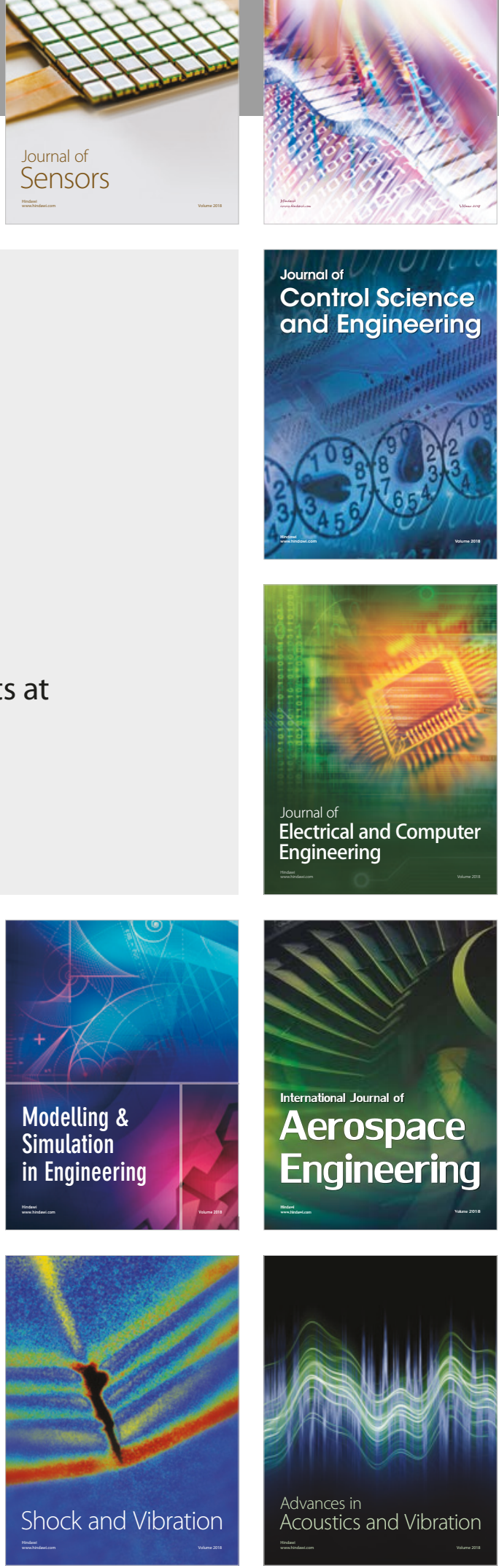